\title{
Caring for Aboriginal patients requires trust and respect, not courtrooms
}

\author{
Lisa Richardson MD MA, Matthew B. Stanbrook MD PhD
}

A recent Ontario court ruling ${ }^{1}$ has affirmed the right of an Aboriginal girl and her family to forgo chemotherapy in favour of traditional Aboriginal medicine. The decision has engendered heated debate among Aboriginal communities, the legal profession and the general public. ${ }^{2}$ This furor must not prevent us from taking this opportunity to reflect on what delivering optimal care to Aboriginal patients really means.

J.J., an 11-year-old Haudenosaunee girl from Six Nations of the Grand River First Nation, began treatment for acute lymphoblastic leukemia at a Hamilton hospital in August 2014. After 10 days of chemotherapy, she and her family turned instead to a traditional Haudenosaunee healer. ${ }^{3}$ Given the proven efficacy of chemotherapy for her disease, which otherwise carries a fatal prognosis, her physicians asked the court to remove J.J. from her parents to compel her to receive treatment. The physicians and hospital were overruled on the basis that doing so would violate J.J.'s constitutional rights.

The blame that has been levelled at all parties must stop. In turning to the court, the hospital and medical team were no doubt driven by fear for the child's life. Despite refusing chemotherapy, J.J.'s family were not uncaring, negligent or ignorant - indeed, child and family services refused to intervene on this basis. Although some people have disputed the correctness of the judge's ruling, it appears to have been a thoughtful decision addressing a complex area of law.

Media coverage has fueled a narrative of polarized paradigms that is unhelpful and misleading, implying false choices. Medical science poses no inherent conflict with Aboriginal ways of thinking. Medical science is not specific to a single culture, but is shared by Aboriginal and non-Aboriginal people alike. Most Aboriginal people seek care from health professionals - but nearly half also use traditional medicines. ${ }^{4}$ Aboriginal healing traditions are deeply valued ancestral practices that emphasize plant-based medicines, culture and ceremony, multiple dimensions of health (physical, mental, emotional and spiritual), and relationships between healer, patient, community and environment. ${ }^{5}$ These beliefs create expectations that Aboriginal patients bring to their health care encounters; these must be respected. Doing so is not political correctness - it is patient-centred care.

Instead, Aboriginal patients continue to feel unwelcome or unsafe in our medical institutions, in some cases being ignored or left to die. ${ }^{6}$ A recent study described the persistent racism, negative stereotyping and a lack of cultural respect Aboriginal people faced within health care institutions. ${ }^{7}$ In addition, Aboriginal people may carry historical trauma from their own or their communities' experiences in medical and educational centres. Both contemporary and historical memo- ries of mistreatment may lead Aboriginal patients to question or mistrust the actions of health care providers.

Trust is essential for medical treatment to be effective, particularly when it involves giving one's child toxic medications with severe adverse effects. Had the court forced J.J. to undergo such treatment, the mistrust, anger and resistance that might have ensued within her community could have greatly compromised any future ability to provide optimal care not only to her, but to all Aboriginal people. For the state to remove a child from her parents and enforce medical treatment would pose serious, possibly lifelong, repercussions for any family, but such action holds a unique horror for Aboriginal people given the legacy of residential schools.

To make medical treatment acceptable to our Aboriginal patients, the health care system must earn their trust by delivering respect. We must ensure that our Aboriginal patients, their families and communities feel welcome, are comfortable selfidentifying as Aboriginal and do not fear judgment based on stereotypes. They must feel safe sharing their wishes to perform ceremonies or pursue traditional healing practices in conjunction with treatment, and these wishes should be accommodated as readily as we would spiritual counselling from a chaplain. All health professionals must know about the ongoing health inequities affecting Aboriginal people and strive to address their collective repercussions. Evaluating quality of care must include the experiences and relationships of our Aboriginal patients with the health care system in addition to disease outcomes.

Aboriginal physicians should have a leading role as cultural translators between their communities and the health care system, and Canada must train more of them. Greater Aboriginal selfdetermination in health care could further transform care. ${ }^{8}$ In the meantime, all health professionals and trainees should make use of existing programs to learn about and practise cultural safety. ${ }^{9}$ If our interactions with our Aboriginal patients can be based on trust and respect, we will have no need of courtrooms.

See references, www.cmaj.ca/lookup/suppl/doi:10.1503/cmaj.141613

Competing interests: For Matthew Stanbrook, see www.cmaj.ca/site/misc /cmaj_staff.xhtml. Lisa Richardson is supported by an AMS Phoenix Fellowship to develop curriculum about cultural safety for Indigenous patients for medical trainees and physicians.

Affiliations: Deputy Editor, CMAJ (Stanbrook); Division of General Internal Medicine and Curricular Co-Lead, Office of Indigenous Medical Education (Richardson), University of Toronto, Toronto, Ont.

Correspondence to: CMAJ editor, pubs@cmaj.ca

CMAJ 2015. DOI:10.1503/cmaj.141613 